\title{
De lessons learned van toezichtrapporten ${ }^{*}$
}

\author{
Annetje Ottow
}

Het rapport van de Commissie Borstlap past in een serie rapporten waarin, naar aanleiding van een incident, terugkijkend een feitelijke en kwalitatieve analyse wordt gedaan over de gang van zaken bij een toezichthouder. Andere rapporten die in dit rijtje thuishoren zijn onder meer: het rapport Icesave (Universiteit van Amsterdam) ${ }^{1}$ het rapport in de DSB-affaire (rapport Commissie Scheltema) ${ }^{2}$ en het onderzoek naar de ondergang van SNS (rapport van de Commissie Hoekstra). ${ }^{3}$ Deze rapporten zijn waardevol, aangezien zij een inkijk geven in de keuken van de toezichthouder, meer transparantie bieden van wat er zoal achter de schermen gebeurt en waardevolle lessen bevatten voor niet alleen de betrokken toezichthouder, maar ook voor andere toezichthouders. In deze bijdrage zullen uit diverse rapporten de lessons learned worden geschetst, waarbij ook buitenlandse rapporten aan de orde komen. Welke lessen kunnen nu zoal uit de verschillende onderzoeksrapporten worden getrokken? Uit de geanalyseerde rapporten komt naar voren dat niet alleen het ontbreken van expertise (de noodzakelijke professionaliteit) de oorzaak kan vormen van het falen van de toezichthouder, maar dat evenzeer de omgeving waarin de experts van de toezichthouder opereren, van invloed is op het handelen of juist het ontbreken daarvan. Deze toezichtomgeving ziet op de interne (toezicht)cultuur, de wijze van besluitvorming binnen de organisatie en de management- en IT-processen. Deze aspecten, die alle nauw met elkaar samenhangen, zal ik in deze bijdrage de revue laten passeren.

\section{Het ontbreken van een toetsingskader}

Deze onderzoeksrapporten bevatten waardevolle analyses over de vraag of in een concreet geval, bijvoorbeeld de ondergang van SNS Bank, sprake is van toezichtfalen. In andere gevallen wordt - na een aaneenschakeling van klachten - een gehele organisatie onder de loep genomen en wordt beoordeeld of de toezichthouder wel goed functioneert, zoals bijvoorbeeld in het rapport over het toezicht door de Inspectie gezondheidszorg. ${ }^{4}$ De benoemde commissie doet een feitenonder-

* Dit artikel is deels gebaseerd op hoofdstuk 6 van het boek van de auteur Market and Competition Authorities. Good Agency Principles, Oxford: Oxford University Press 2015.

1 A.J.C. de Moor-van Vught e.a., De bevoegdheden van De Nederlandsche Bank inzake Icesave, Amsterdam: Universiteit van Amsterdam, 11 juni 2009.

2 Rapport van de Commissie Onderzoek DSB Bank (Scheltema-rapport), Den Haag, 23 juni 2010.

3 R.J. Hoekstra \& J. Frijns, Het rapport van de evaluatiecommissie nationalisatie SNS Reaal, Amsterdam: Uitgeverij Balans 2014.

4 W. Zorgdrager, Van incident naar effectief toezicht. Onderzoek naar de afhandeling van dossiers over meldingen door de Inspectie gezondheidszorg, 19 november 2012. 
zoek en komt tot conclusies en aanbevelingen. Maar waaraan toetst een dergelijke commissie eigenlijk? Wat is het referentiekader?

De rapporten komen op basis van kennis achteraf - zonder een duidelijk toetsingskader - tot niet-juridische inzichten, waarbij geconstateerd wordt wat er 'fout' is gegaan. Ze geven een oordeel over wat er is gebeurd en verbinden hieraan conclusies, met soms verstrekkende gevolgen. Vanuit een juridisch oogpunt is dit onbevredigend, aangezien de toezichthouder achteraf met toetsingscriteria wordt geconfronteerd, die op voorhand niet altijd duidelijk zijn. Hierop wijst de Commissie Scheltema terecht in haar DSB-rapport: ${ }^{5}$

'een en ander brengt met zich mee dat de oordelen van de Commissie niet zijn vervat in juridische termen en daarin ook niet zonder meer kunnen worden vertaald. (...) de Commissie stond wel voor het probleem dat zij moest handelen zonder dat daarvoor een voldoende (professioneel) referentiekader beschikbaar was. (...) Een probleem dat bij een onderzoek als dit onvermijdelijk betreft het feit dat handelen beoordeeld moet worden tegen de achtergrond van de gegevens die toen ter beschikking stonden, terwijl nu bekend is hoe het verder is gegaan. (...) Achteraf is duidelijk welke risico's zich hebben verwezenlijkt en dus om aandacht vroegen, maar de toezichthouders moeten hun keuzes vooraf maken op basis van een inschatting van die risico's.'

Dus met hindsight wordt een analyse over het optreden of nalaten van de toezichthouder gemaakt: met de kennis van nu worden de feiten van toen bekeken. Dit kleurt niet alleen de wijze waarop het verleden wordt beoordeeld, maar heeft ook invloed op de selectie van het materiaal dat wordt onderzocht. ${ }^{6}$ Dit is ook tevens de beperking van het onderzoek van de Commissie Borstlap: het uitgangspunt vormde het bezwaarschrift van de heer Gotlieb. Bij dergelijke onderzoeken is voorzichtigheid ten aanzien van de te trekken conclusies dan ook geboden en dient de onderzoekscommissie gespitst te zijn op een voldoende feitelijke analyse van alle omstandigheden en het toepassen van hoor en wederhoor.

Kennelijk hanteren de onderzoekscommissies een zeker uitgangspunt dat als 'goed toezichthouderschap' moet worden bestempeld en waaraan de onderzoekscommissie haar bevindingen afmeet. In Nederland hebben wij hiervoor geen standaardtoetsingskader. Het verder ontwikkelen van een duidelijker toetsingskader kan de waarde van deze rapporten aanzienlijk vergroten. De beginselen van goed toezichthouderschap, zoals door mij verwoord in mijn boek Good agency principles, kunnen hiervoor als een leidraad dienen: de beginselen van legaliteit, onafhankelijkheid, transparantie, effectiviteit en verantwoordelijkheid. In mijn boek heb ik deze good agency principles aangeduid als de 'LITER principles': legality (L), independence (I), transparency (T), effectiveness (E) en responsability (R). Ook het proefschrift van Margot Aelen, Beginselen van goed toezicht, zoals in dit nummer van het Tijdschrift voor Toezicht besproken door Robben, biedt hiervoor vele handvat- 
ten. ${ }^{7}$ Deze toezichtbeginselen, de LITER-beginselen, vormen tezamen een algemeen richtingskader, waarnaar de toezichthouder zich bij zijn handelen kan richten en waaraan stakeholders de toezichthouder kunnen houden. Ook voor onderzoekscommissies kunnen zij een referentiekader voor hun onderzoek vormen. Deze beginselen zijn afgeleid uit diverse nationale, Europese en internationale bronnen, die ik in mijn boek heb onderzocht. Uit het onderzoek blijkt dat er universele normen gelden, die voor economische toezichthouders in de loop der jaren zijn ontwikkeld. Ook voor andere toezichthouders zijn deze relevant en toepasbaar. In dit artikel ligt de focus op de operationele lessen die uit de diverse geselecteerde onderzoeksrapporten zijn af te leiden, met hier en daar een verwijzing naar de relevante toezichtbeginselen. Daarbij springen de beginselen van onafhankelijkheid, transparantie en effectiviteit in dit kader het meest in het oog.

\section{De interne toezichtcultuur}

Cruciaal voor het goed functioneren van een toezichthouder is de interne toezichtcultuur, die gebaseerd dient te zijn op integriteit, onafhankelijkheid en objectiviteit. Indien een van deze elementen ontbreekt, zal dit negatieve gevolgen hebben voor de autoriteit en het gezag van de toezichthouder. Dit heeft het Borstlaprapport wel aangetoond: doordat er twijfel bestond over de integriteit van de bestuursleden en de interne cultuur binnen de NZa raakte zij gaandeweg steeds meer gezag kwijt, hetgeen tot een disfunctioneren van de toezichthouder kan leiden. Enige twijfel over de onafhankelijkheid kan vergaande gevolgen voor het functioneren hebben. Leiderschap, het introduceren van de juiste interne procedures en het daarnaar handelen om deze onafhankelijkheid te garanderen, vormen voor goed toezichthouderschap essentiële ingrediënten. In dit verband kan ook worden verwezen naar de bijdragen in dit nummer van Janka Stoker \& Floor Rink en Caelesta Braun.

Het belang van de juiste tone at the top dient niet te worden onderschat. Indien leiders van een organisatie niet het juiste voorbeeld geven en weinig oog hebben voor compliance binnen de eigen organisatie, zal uiteindelijk een uitholling van het gezag van de toezichthouder plaatsvinden. ${ }^{8}$ De normen die de toezichthouder aan de onder toezicht gestelde ondernemingen oplegt, dienen ook voor de toezichthouder zelf te gelden. Zo bleek de FCA (Financial Conduct Authority) de opgestelde regels voor het publiceren van koersgevoelige informatie door financiële

7 M. Aelen, Beginselen van goed toezicht. Gedefinieerd, verklaard en uitgewerkt voor het toezicht op de financiële markten, Den Haag: Boom Juridische uitgevers 2014.

8 Een ander voorbeeld uit de Amerikaanse praktijk betrof de US Minerals Management Service, waar sprake was van een ernstige vorm van capture. Zie C. Carrigan, Captured by Disaster? Reinterpreting Regulatory Behavior in Shadow of the Gulf Oil Spill, in: D. Carpenter \& D. Moss (eds.), Preventing Regulatory Capture. Special Interest Influence and How to Limit it, New York: Cambridge University Press 2014. 
instellingen zelf niet te volgen bij het publiceren van haar toezichtjaarplan. ${ }^{9}$ Door een onzorgvuldige publicatie van deze koersgevoelige informatie kelderde de beurskoers van verzekeringsmaatschappijen op basis van verkeerde (onjuist geïnterpreteerde) informatie.

\section{Besluitvormingsprocessen}

Gerelateerd aan de toezichtcultuur is het juist inrichten van besluitvormingsprocedures. Uit de onderzochte rapporten komen specifiek drie elementen sterk naar voren: (1) het probleem van tunnelvisie, (2) het blijven uitstellen van interventies en (3) het feit dat besluiten worden genomen op een te laag niveau binnen de organisatie. ${ }^{10}$ Deze aspecten kunnen belangrijke invloed hebben op de kwaliteit van het besluitvormingsproces en de uitkomst van deze processen.

In de eerste plaats het voorkomen van vooringenomenheid bij het nemen van besluiten. Procedures bij het besluitvormingsproces dienen bias ${ }^{11}$ of tunnelvisies zo veel mogelijk te voorkomen. Daar waar toezicht en onderzoek in een hand gaan, dient te worden voorkomen dat er sprake is van vooringenomenheid bij het handhavingsproces. ${ }^{12}$ Handhaving dient objectief en onafhankelijk plaats te vinden. Slechts dan zal het toezicht effectief kunnen zijn. Een bekend fenomeen bij handhaving is de zogenoemde enforcement bias, waarbij het onderzoeksteam gefocust is op het vinden van een overtreding en bewijs hierop selecteert. In het Condor-rapport van de Office of Fair Trading wordt hier specifiek op gewezen. ${ }^{13}$ Dit Condor-rapport is overigens bijzonder, aangezien dit een van de weinige (door mij gevonden) rapporten is dat door de toezichthouder zélf over het eigen functioneren is opgesteld én openbaar is gemaakt. Slechts het hierna te bespreken rapport inzake Northern Rock betreft eveneens een intern, gepubliceerd rapport. In het kader van transparantie van het toezicht is deze zelfreflectie toe te juichen en verdient deze navolging. ${ }^{14}$

9 Het Davis report: Report of the inquiry into the events of 27/28 March 2014 relating to the press briefing of information in the Financial Conduct Authority's 2014/15 Business plan, Simon Davis, Clifford Chance LLP, London: 20 November 2014, p. 24, paragraph 4.56: 'The procedures which exist within the Supervision and Communications Divisions (...) relating to price-sensitive information are inadequate and not of the standard which the FCA expects of those it regulates.'

10 A.T. Ottow, Market and Competition Authorities. Good Agency Principles, Oxford: Oxford University Press 2015, p. 207-209.

11 Zie R.M. Jansen \& M. Aelen, Bias in toezicht: wat zijn het en hoe kunnen we ermee omgaan?, TvT 2015, nr. 1, p. 5-21.

12 Ottow 2015, p. 123-130 en 155-156.

13 Intern rapport van de Office of Fair Trading (nu opgegaan in de Competition and Markets Authority) Project Condor Board Review, London, October 2010. Dit is een intern rapport, dat werd opgesteld door drie non-executive board members naar aanleiding van het verliezen van de strafzaak R v. Burns and Others.

14 Een dilemma kan hier vanzelfsprekend zijn dat het naar buiten brengen van dergelijke analyses over het eigen handelen van de toezichthouder aanleiding zou kunnen zijn tot claims van gedupeerde partijen. Een toezichthouder zal dus over het algemeen voorzichtig zijn met het naar buiten brengen van dergelijke bevindingen. 
De interne onderzoekscommissie van OFT wijst op de noodzaak een 'fresh pair of eyes' gedurende het gehele besluitvormingsproces te organiseren. Deze zaak betrof het starten van strafzaken tegen individuele directieleden van British Airways voor een vermeend prijskartel tussen Bristish Airways en Virgin Atlantic. Uiteindelijk moest OFT gedurende het strafproces voor de rechter de zaak intrekken vanwege een opeenstapeling van fouten. Deze fouten waren gedurende het voorbereidingsproces niet of onvoldoende onderkend. In het rapport werd geconstateerd dat OFT niet alleen te weinig beslissingsmomenten ("clear stop/go decision points') had ingebouwd, maar dat de medewerkers over te weinig strafrechtelijke expertise beschikten om de zaak goed te kunnen beoordelen. Zo was er bijvoorbeeld te weinig ervaring met het verhoren van getuigen, hetgeen in strafzaken cruciaal is.

Een ander element in het kader van onderzoek en handhaving betreft het zogenoemde uitstelgedrag. Dit ziet op het te lang in overleg blijven met de onder toezicht gestelde onderneming en ingrijpen wordt uitgesteld. Dit was bijvoorbeeld het geval bij het toezicht op Icesave Bank, de DSB Bank en SNS Reaal. In alle drie de onderzoeksrapporten over het toezicht op deze financiële instellingen constateren de onderzoekscommissies dat er te lang is geprobeerd (informele) oplossingen te zoeken en dat de toezichthouder eerder had moeten doorpakken. Hard ingrijpen werd te lang uitgesteld in de hoop dat men door overleg nog tot oplossingen zou kunnen komen. Een hiermee vergelijkbaar probleem is dat van 'stranded costs bias': een team blijft doorgaan met het onderzoek omdat men al zoveel in het dossier heeft geïnvesteerd dat een besluit te stoppen als 'te kostbaar' wordt ervaren. Men denkt nog voldoende nieuwe informatie te kunnen verzamelen om de zaak rond te kunnen krijgen. Dit was bijvoorbeeld het geval in de genoemde Condor-zaak. Het stopzetten van een zaak blijkt in de praktijk niet altijd makkelijk te zijn. Dit vergt van het senior management dat er voldoende betrokkenheid is en er op gezette tijden momenten worden ingebouwd om te beoordelen of men wel met een zaak door moet gaan ('clear stop/go decision points').

Uit het SNS-rapport van de Commissie Hoekstra en het Condor-rapport, maar ook het recente Davis-rapport ${ }^{15}$ kan nog een andere, duidelijke les worden geleerd: besluiten dienen op het juiste niveau binnen de organisatie te worden genomen en op tijd te worden geëscaleerd. Senior management en de leden van bestuur dienen tijdig bij de besluitvorming te worden betrokken om risico's op de juiste wijze te kunnen inschatten. Indien het proces intern niet kritisch wordt gevolgd, kan het voorkomen dat een te eenzijdige kijk op de zaak ontstaat of dat er niet op de juiste wijze wordt gehandeld of dat te laat wordt ingegrepen. Deze lessen trok ook de interne commissie van de OFT in de zaak Condor. Het proces was onvoldoende gevolgd door de board van de OFT en deze had zich er niet van vergewist of er voldoende kennis in huis was om een dergelijke (nieuwe en grote) zaak te kunnen behandelen. Ook uit het rapport Davis over de onjuiste publicatie van een persbericht en het betrekken van de pers bij de publicatie van het nieuwe 
jaarplan van de toezichthouder, blijkt dat het bestuur onvoldoende geïnvolveerd was. De zaak werd in eerste instantie slechts behandeld door de communicatieafdeling en noch de experts noch het bestuur waren voldoende op de hoogte. Ook nadat de fout over de publicatie was geconstateerd, werden de boardleden niet direct betrokken en was er geen noodplan ('emergency action plan') beschikbaar. ${ }^{16}$ Hierdoor werd de ernst van de zaak onderschat en werden er te laat schadebeperkende maatregelen getroffen. In deze zaak constateert de onderzoeker dat de FCA gekozen had om communicatie en transparantie als een 'regulatory tool' in haar handhavingsstrategie in te zetten, maar daarbij onvoldoende oog had gehad voor de bescherming van vertrouwelijke of koersgevoelige informatie. Transparantie is een belangrijk toezichtbeginsel, maar dient hand in hand te gaan met voldoende waarborgen ten aanzien van vertrouwelijkheid. ${ }^{17}$

\section{Professionalisering: expertise}

Expertise en voldoende professionaliteit zijn noodzakelijke ingrediënten om als toezichthouder onafhankelijk en effectief te kunnen opereren. De juiste expertise dient aanwezig te zijn om goede besluiten te kunnen nemen. Dit lijkt een open deur, maar uit de diverse rapporten blijkt dat de expertise niet altijd aanwezig is. Er kan sprake zijn van onvoldoende medewerkers doordat budgetten drastisch zijn ingeperkt of door reorganisatie. Dit was bijvoorbeeld het geval bij de fusie tussen de Voedsel en Warenautoriteit, de Algemene Inspectiedienst en de Plantenziektenkundige Dienst in de NVWA (de Nederlandse Voedsel en Warenautoriteit). De fusie had moeten leiden tot grote besparingen, hetgeen echter ten koste ging van voldoende kundig personeel en het verdwijnen van handhavingsexpertise tot gevolg had. ${ }^{18}$ Reorganisaties kunnen ook leiden tot te veel roulatie van personeel, hetgeen ook het wegvloeien van expertise kan betekenen. Tevens dienen besturen van toezichthouders alert te zijn indien er te veel ervaren personeel tegelijkertijd doorstroomt naar buiten (bijvoorbeeld bij een schaarste op de arbeidsmarkt). De vraag is of er dan voldoende ervaren medewerkers kunnen worden geworven om dit vertrek op te vangen. Het personeelsbeleid dient hierop voldoende in te spelen.

Het ontbreken van voldoende expertise deed zich tevens voor in de SNS-zaak, waarbij het team te veel afging op de informatie die door de onder toezicht gestelde financiële instelling, SNS, zelf werd aangeleverd. Het team van DNB deed te weinig eigen onderzoek en het ontbrak het team aan expertise om dit op eigen merites te kunnen beoordelen. ${ }^{19}$ Hierdoor zag het team te laat hoe ernstig de situatie bij SNS Bank was. Ditzelfde deed zich voor in de zaak Northern Rock in

16 Davis report, p. 30-31.

17 Ottow 2015, p. 7 en p. 82-86.

18 Algemene Rekenkamer, Toezicht bij de Nederlandse Voedsel- en Warenautoriteit na de fusie, Den Haag 2013.

19 SNS-rapport. R.J. Hoekstra \& J. Frijns, Het rapport van de evaluatiecommissie nationalisatie SNS Reaal, Amsterdam: Uitgeverij Balans 2014. 
Engeland. ${ }^{20}$ In dit rapport, dat door de interne audit division van de financieeltoezichthouder in Engeland, de Financial Services Authority (FSA), was opgesteld over het eigen toezicht op de bank Northern Rock, komt FSA tot de conclusie dat als gevolg van een reorganisatie niet de juiste mensen toezicht hielden op deze financiële instelling. Hierdoor waren zij niet in staat de risico's voldoende in te schatten en was deze bank ten onrechte als een financiële instelling met een laag risicoprofiel aangemerkt. Het door FSA ingestelde risicogebaseerd toezicht was hierdoor niet adequaat en niet effectief. Het kiezen en uitzetten van een handhavingsstrategie is nuttig, maar het op de juiste wijze implementeren is vervolgens geen sinecure. ${ }^{21}$ In deze evaluatierapporten komt tevens naar voren dat er vaak wel kennis aanwezig is in individuele dossiers, maar dat deze kennis niet op een geaggregeerd niveau bijeen wordt gebracht. Dit maakt dat de toezichthouders systeemrisico's slecht inschatten en trends niet of niet tijdig onderkennen. Coördinatie van informatie en 'het integreren van meldingen in het risico-gestuurd toezicht $^{\prime 22}$ is onontbeerlijk. Processen dienen hierin te voorzien.

Ook dienen afdelingen voldoende met elkaar samen te werken en informatie te delen, hetgeen niet altijd het geval blijkt te zijn. Het blijven investeren in mensen en hun opleiding vormt daarnaast een belangrijk element voor de kwaliteitsgarantie. Dit kan gebeuren door bijvoorbeeld een eigen academie op te zetten, zoals dit bijvoorbeeld het geval is bij de DNB, maar ook bij de Autoriteit Consument en Markt (ACM) en bij de Competition and Markets Authority (CMA) of in samenwerking met andere toezichthouders. Voldoende gekwalificeerd personeel en een permanente opleiding zijn onmisbaar om goede besluiten te kunnen nemen en een gezamenlijke toezichtcultuur te (blijven) ontwikkelen. In het rapport Condor wordt opgemerkt dat het inschakelen van expertise bij derden (zoals advocaten) onvoldoende is. Men zal ook zelf de expertise in huis moeten hebben, ook om ervoor te zorgen dat expertise 'beklijft' binnen de eigen organisatie. Toezichthouders dienen lerende organisaties te zijn, die investeren in de opleiding van hun mensen en het ontwikkelen van kennis en vaardigheden, maar ook leren van fouten en zichzelf blijven vernieuwen.

\section{Management en IT-processen}

Deze professionalisering vergt ook investeren in management- en IT-processen. Het belang van IT bij toezicht dient niet te worden onderschat. Het beschermen van (vertrouwelijke) opgeslagen data, het analyseren van big data en het toegang verstrekken tot opgeslagen data zijn in de dagelijkse praktijk van een toezichthouder steeds belangrijkere activiteiten; activiteiten die in sterke mate afhankelijk zijn van de juiste IT-infrastructuur en IT-kennis. Dit vergt de nodige investeringen en het blijven updaten van de infrastructuur en software. Het verwaarlo-

20 FSA Internal Audit Division, The supervision of Nothern Rock: a lessons learned review, London 2008.

21 Ottow 2015, hoofdstuk 5.

22 Rapport van W. Sorgdrager inzake IGZ, p. 59. 
zen van deze processen zet de toezichthouder niet alleen op achterstand, maar kan ook directe gevolgen hebben voor zijn primaire proces: het toezicht houden. In vele van de bestudeerde rapporten blijkt een falend IT-systeem of het verwaarlozen van IT-security het besluitvormingsproces of de compliance-cultuur te kunnen ondermijnen. Zo blijkt uit het rapport van de Commissie Borstlap dat er te weinig oog was voor het beschermen van privacygevoelige informatie, hetgeen ernstige gevolgen voor betrokkenen kan hebben. Vertrouwelijke informatie van individuen maar ook van ondernemingen moet bij toezichthouders in vertrouwde handen zijn: processen en de IT dienen hierop te zijn ingesteld. Dit vergt grote investeringen, waarvoor niet altijd de budgetten voorhanden zijn of de vereiste expertise aanwezig is. In de Condor-zaak was de analyse van de dataroom (met alle big data en vertrouwelijke informatie) door OFT uitbesteed aan experts van de betrokken partijen bij het onderzoek. Tijdens de gerechtelijke procedure kwam men erachter dat een groot deel van deze data onvoldoende ontsloten was, hetgeen ertoe leidde dat de zaak moest worden ingetrokken. In het rapport Sorgdrager wordt geconstateerd dat bij de IGZ innovaties in processen en ondersteunende ICT-voorzieningen elkaar in hoog tempo hadden opgevolgd en vernieuwingen in gang waren gezet zonder dat het voorafgaande was afgerond. Ook was er te weinig verbinding in het proces en de ICT-voorzieningen en de meldingen die binnen kwamen. Door dit alles was er te weinig ontsluiting van data, bestond er te weinig oog voor het systeemtoezicht en was er onvoldoende termijnbewaking (te lange doorlooptijden). Ook bij fusies tussen toezichthouders is de IT vaak een heikel punt. IT vergt bij fusieprocessen speciale aandacht. Indien dit niet goed is georganiseerd kan de integratie stroef lopen en is het niet goed mogelijk processen te integreren. Uit het onderzoek naar de fusie bij de NVWA volgt dat de IT-systemen van de gefuseerde autoriteiten niet op elkaar aansloten. Dit leidde tot aanzienlijke extra kosten en te weinig coördinatie van de handhavingsacties.

\section{Conclusie}

Uit de geanalyseerde onderzoeksrapporten kan worden afgeleid dat zaken binnen toezichthouders 'mis' kunnen gaan door een samenstel van factoren en een samenloop van omstandigheden. Hoewel de zaken op zichzelf staan, zijn er toch duidelijke overeenkomsten te identificeren en algemene aandachtsgebieden te benoemen. Naast het ontbreken van de noodzakelijke aanwezigheid van expertise en ervaring, betreft het belangrijkste probleem toch het verwerkingsproces van informatie binnen de organisatie en de juiste interpretatie ervan. De juiste samenstelling van teams en de tijdige escalatie naar senior management is eveneens cruciaal gedurende het besluitvormingsproces. Investering dient niet alleen plaats te vinden in de aanwezigheid van kennis binnen de organisatie, maar ook in IT-processen en infrastructuur. Ook toezichthouders worden steeds afhankelijker van het analyseren van big data en het opslaan van grote bestanden aan (vertrouwelijke) informatie. Hiervoor dient voldoende aandacht te zijn. Ook toezichthouders maken wel eens fouten, maar belangrijker is wat men van deze fouten leert. Rapporten zoals dat van de Commissie Borstlap dragen bij aan het lerend 
Annetje Ottow

vermogen van deze organisaties en bieden meer transparantie en accountability over het toezicht. Bovendien vormen ze een bouwsteen voor het vaststellen van wat goed toezichthouderschap dient te zijn. 